\title{
PERUBAHAN FUNGSI DAN MAKNA RITUAL TOLAK BALA DIDESA BAGAN SERDANG KECAMATAN PANTAI LABU KABUPATEN DELI SERDANG
}

\author{
Sutikno \\ Universitas Muslim Nusantara Al-Washliyah \\ Jl.Garu II Sisingamangaraja \\ sutikno.stf@Gmail.Com
}

\begin{abstract}
Abstrak
Penelitian ini menggunakan metode kualitatif, dengan pendekatan kajian budaya yang bersifat kritis, interdisipliner, multidimensional. Hasil penelitian menunjukkan bahwa perubahan fungsi dan makna ritual tolak bala ini bukan hanya menjadikan ritual ini yang sebelumnya bukan barang komoditi menjadi barang komoditi tetapi perubahan fungsi dan makna ritual tolak bala berkaitan pula dengan proses produksi, distribusi dan konsumsi. Faktor penyebab perubahan fungsi dan makna ritual tolak bala pada etnik Melayu Pantai Labu di di Desa Bagan Kecamatan Pantai Labu Kabupaten Deli Serdang Provinsi Sumatera Utara yaitu sifat masyarakat yang terbuka, dan kreativitas masyarakat, media massa, dan ekonomi. Dampak dan makna perubahan ritual tolak bala yaitu berdampak terhadap kehidupan sosial budaya masyarakat yang cenderung merugikan ritual tolak bala yang dikomersialisasikan dan kaburnya identitas budaya. Disamping itu strategi pewarisan ritual ritual tolak bala pada etnik Melayu Pantai Labu ini dilakukan dalam tiga bentuk yaitu (1) pemberdayaan (2) dokumentasi dan (3) pengembangan.
\end{abstract}

Kata Kunci: Perubahan Fungsi dan Makna, Ritual Tolak Bala, Etnik Melayu Pantai Labu.

\begin{abstract}
This study uses a qualitative approach that is critical cultural studies, interdisciplinary, multidimensional. The results show that changes in function and meaning of starting reinforcements ritual is not only to make these rituals that were previously not commodity items become commodities but changing the function and meaning of ritual starting reinforcements also related with the process of production, distribution and consumption. Factors causing changes in the function and meaning of ritual starting reinforcements on ethnic Malays in the village Pantai Labu Labu Beach Bagan District of Deli Serdang North Sumatra province that is the nature of an open society, and creativity of society, mass media, and the economy. The impact and meaning of the ritual changes starting reinforcements that have an impact on social and cultural life of society that tend to harm the ritual starting reinforcements are commercialized and blurring of cultural identity. Besides, the strategy inheritance rituals starting reinforcements on ethnic Malay Pantai Labu is done in three forms: (1) empowerment (2) documentation, and (3) development.
\end{abstract}

Keywords: Changes In Function And Meaning, Ritual Starting Reinforcements, And Ethnic Malay Pantai Labu.

\section{PENDAhUluan}

1.1. Latar Belakang Masalah

Ritual tolak bala di desa Bagan Kecamatan Pantai Labu Kabupaten Deli Serdang Provinsi Sumatera merupakan tradisi yang ada sejak zaman nenek moyang dan diwariskan kepada generasi penerus untuk dilestarikan. Ritual tolak bala ini termasuk dalam folklor sebagian lisan. Folklor sebagian lisan adalah folklor yang bentuknya merupakan campuran unsur lisan dan 
bukan lisan (Danandjaja, 2002:195). Pada pelaksanaan upacara adat dibutuhkan sesaji. Sesaji merupakan aktualisasi dari pikiran, keinginan, dan perasaan pelaku untuk lebih mendekatkan diri kepada Tuhan. Sesaji juga merupakan wacana simbol yang digunakan sebagai sarana untuk negosiasi spiritual kepada hal-hal gaib. Hal ini dilakukan agar makhlukmakhluk halus di atas kekuatan manusia tidak mengganggu. Dengan pemberian makan secara simbolik kepada roh halus, diharapkan roh tersebut akan jinak, dan mau membantu hidup manusia (Endraswara, 2003:195).

Sebagai salah satu tradisi lisan ritual tolak bala, baik dalam historisnya maupun perkembangan zamannya, tampaknya tidak luput dari adanya perubahan-perubahan. Sentuhan modernisasi yang semakin mengglobal dalam kehidupan masyarakat mengakibatkan munculnya sikap pragmatisme dalam memaknai hakikat dari ritual, seperti kepraktisan, efisiensi, dan keberlanjutan. Implikasi dari sentuhan modernisasi terhadap bidang pendidikan, dan mata pencaharian di Kecamatan Pantai Labu menyebabkan terjadinya perubahan-perubahan tersebut.

\section{METODOE}

Penelitian ini menggunakan metode kualitatif. Metode kualitatif adalah prosedur penelitian yang menghasilkan data deskriptif berupa data tertulis atau lisan dari orang-orang yang diamati. Berdasarkan filsafat rasionalisme bahwa suatu ilmu yang valid diperoleh dari pemahaman intelektual dan kemampuan berargumentasi secara logis. Dalam realitas empirik adalah tunggal (sama dengan positivism penganut paham monism) tetapi realitas tersebut tidak diinterpretasikan dari prespektif (Muhadjir, 2000:83-84). Penelitian ini dilaksanakan di Desa Bagan Serdang,
Kecamatan Pantai Labu pada rentang waktu antara bulan Agustus 2016 Oktober 2016.

Melalui metode kualitatif, memungkinkan peneliti untuk menata, mengkritisi, dan mengklarifikasikan data yang menarik. Dengan demikian, penelitian kualitatif ini membimbing peneliti untuk memperoleh penemuanpenemuan yang tidak terduga sebelumnya dan membangun kerangka teoritis yang baru (Endraswara, 2003:14-15). Jenis data dalam penelitian ini adalah data kualitatif berupa teks, lambang dan simbol serta unsur-unsur lainya yang berhubungan dengan ritual tolak bala di Kecamatan Pantai Labu dan ditunjang dengan data kuantitatif. Data kualitatif diperoleh dari hasil obsevasi, wawancara. Data yang digunakan adalah data tentang ritual tolak bala. Sumber data primer adalah para informan. Sumber data sekunder adalah ritual pelaksanaan studi dokumen berupa hasil-hasil penelitian terdahulu, buku-buku, laporan-laporan yang berhubungan dengan ritual tolak bala di Kecamatan Pantai Labu Kabupaten Deli Serdang, Sumatera Utara.

Penentuan informan dalam penelitian ini dilakukan melalui beberapa jaringan, seperti informasi dari masyarakat dan budayawan yang ada di lokasi penelitian yang dipilih secara selektif berdasarkan sejumlah kriteria tertentu. Instrumen penelitian ini adalah pedoman wawancara dan kartu-kartu data. Pengumpulan data dalam penelitian ini dilakukan secara triangulasi yakni observasi, wawancara mendalam studi dokumen dan teks atau mantra dan proses analisis data dimulai dengan menelaah seluruh data yang diperoleh melalui berbagai sumber, yaitu wawancara, pengamatan dan perekaman dan catatan lapangan. 


\section{HASIL DAN PEMBAHASAN}

Analisis struktural fungsional ritual tolak bala untuk pengobatan mencakup konteks budaya, konteks sosial, konteks situasi, dan konteks ideologi.

Konteks budaya penyelengaraan ritual turut mempengaruhi teks mantra yang digununakan. Misalnya mantra pada ritual pengobatan tradisional tentu berbeda dengan mantra yang digunakan dalam upacara kematian. Ini disebabkan oleh perbedaan tujuan yang ingin dicapai dalam menyelenggarakan ritual yang dimaksud. Pada ritual pengobatan tradisional, teks mantra yang digunakan berisi permohonan kepada Tuhan Yang Maha Kuasa dan maupun mahluk gaib atau roh-roh halus agar diberi rezki, umur panjang, kesehatan, kehidupan yang lebih baik, kekuatan, serta dijauhkan dari segala halangan saat peserta ritual mencari kebutuhan hidupnya. Dengan demikian, kita dapat memahami bahwa penggunaan sebuah teks mantra dalam kegiatan ritual tergantung jenis ritualnya.

Konteks sosial mengacu pada faktor-faktor sosial yang mempengaruhi atau menggunakan teks. Faktor-faktor sosial itu berhubungan dengan perbedaan jenis kelamin, kelas sosial, suku, usia, dan sabagainya. Kontek sosial yang dimaksud dalam penelitian ini adalah orang-orang yang terlibat dalam suatu ritual baik itu sebagai pelaku, pengelola, penikmat, dan bahkan komunitas pendukungnya.

Hal ini mengacu pada pada waktu, tempat, dan penggunaan teks. Deskripsi konteks situasi waktu akan menghasilkan waktu pelaksanaan, pertunjukan, dan performansi sebuah tradisi lisan baik dari segi pembagian waktu yang mencakup:

- Waktu dalam Membawakan Mantra

- Tempat Pembacaan Mantra
- Peristiwa dalam membawakan mantra

- Pelaku dalam membawakan mantra

- Pelaku dalam membacakan mantra pengobatan, hanya pawang saja yang dapat membaca mantra ritual tolak bala untuk pengobatan penyakit.

- Perlengkapan dalam membawakan mantra

- Pakaian untuk membawakan Mantra tolak bala untuk pengobatan

- Cara Membawakan Mantra

\subsection{Fungsi}

Peneliti menemukan beberapa fungsi pembacaan mantra dan penggunaan unsur-unsur material dalam ritual pengobatan tradisional.

1. Fungsi Pembacaan Mantra

Dalam ritual tolak bala pengobatan penyakit, mantra memiliki fungsi berikut:

- sebagai sarana penghubung antara peserta ritual dengan Tuhan;

- sarana penghubung dengan Nabi Adam dan Nabi Muhammad.

- sebagai sarana penghubung dengan malaikat.

- sebagai saran penghubung dengan makhluk ghaib.

Tujuan pembacaan mantra di atas adalah; (1) agar Allah SWT dapat mengabulkan permintaan peserta ritual tolak bala yakni diberi kesehatan, kelancaran rezki, kekuatan, umur panjang, serta dijauhkan dari segala marah bahaya; (2) agar Nabi Adam dan Nabi Muhammad menjadi saksi atas permintaan yang diinginkan oleh peserta ritual; (3) agar malaikat mencatat semua apa yang diinginkan oleh peserta ritual; (4) agar mahluk gaib tidak menjadi penghalang peserta ritual dalam menjalangkan kehidupannya.

2. Unsur-Unsur Material

Adapun simbol yang dimaksud adalah sebagai berikut. 
- Sebagai alat untuk menyimbolkan waktu bahwa 1 tahun terdiri atas 12 bulan.

- Sebagai alat persembahan pada mahluk ghaib.

- Menyimbolkan benteng pertahanan yang melindungi peserta ritual terhadap gangguan dari luar (roh-roh jahat).

- Sebagai simbol penghubung antara peserta ritual dengan Nabi Adam.

- Menyimbolkan kesucian Nabi Adam dan Nabi Muhammad.

- Sebagai tanda baik atau tidaknya ritual yang sedang dilakukan.

- Sebagai simbol peralatan yang digunakan untuk mencari kebutuhan hidup.

4.2 Sistem Nilai dalam Ritual Tolak Bala

\section{Nilai Sosial}

Jenis ritual tolak bala pengobatan penyakit ini cukup diikuti oleh satu anggota keluarga. Keadaan demikian merupakan salah faktor pendukung yang dapat membangun satu tatanan nilai dalam ruang lingkup keluarga yang memungkinkan terbentuknya kerjasama dan kekompakan di antara mereka. Ketika suatu kelompok berkumpul dengan tujuan yang sama, tentu dapat melahirkan ikatan emosional antar sesama anggotanya dan bermuara pada kesadaran tentang pentingnya orang lain terhadap dirinya.

Nilai sosial berorientasi kepada berbagai bentuk hubungan sosial, sikap bertanggung jawab terhadap kelompok, kasih sayang, sikap loyal, dan bersedia berkorban dan berpatisipasi dalam kehidupan sosial. Nilai sosial akan muncul pada seseorang jika merasakan kebutuhan pentingnya orang lain terhadap keberadaan dirinya.

2. Nilai Psikologis dan Pedagogis

Rasa sombong yang ditunjukan oleh seorang individu ataupun kelompok diesebabkan oleh banyak faktor namun pada intinya adalah ia lupa tentang hakikat dirinya sebagai manusia yang memiliki kekurangan. Manusia yang sadar tentang hal itu, melakukan berbagai upaya untuk menjadikan dirinya sebagai mahluk berjiwa besar dan mengakui orang lain sama dengan dirinya dengan cara malalui jalur pendidikan formal maupun non-formal.

Pada jalur non-formal, seorang individu pertama kali diperkenalkan dengan lingkungan keluarga dan masyarakat tempat ia hidup. Melalui dua lingkungan tersebut ia pula dapat mengenal tatanan nilai yang harus dipegang teguh sebagai seorang individu dalam kehidupan berkelompok. Pemahaman tentang nilai ini, dibentuk melalui berbagai aktifitas sosial salah satunya adalah ritual pengobatan tradisional. Sebagaimana yang dijelaskan pada bab sebelumnya ritual tersebut mengajarkan pada pemilik tradisi tentang kekuasaan Tuhan atas mahluk-Nya serta kekuasaan-kekuasaan lain yang bersifat abstrak (di luar jangkauan panca indra manusia). Hal demikian dapat memungkinkan pemilik tradisi untuk tidak bersikap sombong. Nilai pedagogis disebut juga nilai pendidikan kandungannya dapat memberi inspirasi atau ide untuk pemenuhan kebutuhan manusia dengan belajar dari prinsipprinsip atau aturan-aturan yang berlaku.

3. Nilai Religius

Dalam mantra ritual tolak bala pengobatan nilai religius dapat dilihat pada penggalan mantra berikut.

Bukan aku nan punya penawar

Tawar Allah tawar Muhammad

Tawar Baginda Rasulullah

Kabul berkat Lailahaillallah, Muhammadurrasullulah

Baris 1 dan 2 pada penggalan mantra di atas, menggambarkan diri seorang pembaca mantra bahwa kaki dan tangan dimilikinya tidak mempunyai kekuasaan untuk 
mengabulkan permintaan orang yang dibacakannya. Akan tetapi yang mempunyai kekuasaan itu adalah Tuhan Yang Maha Kuasa. Pada baris 4 berupa permohonan yang disampaikan pembaca mantra kepada Tuhan Yang Maha Kuasa selaku penguasa alam yang dapat mengabulkan permintaan manusia.

Bunyi mantra ini memberikan suatu bukti bahwasanya mantra ritual tolak bala pengobatan dalam masyarakat Melayu Pantai Labu bukan hanya berisi permohonan berakaitan dengan kebutuhan hidup sehari-hari, akan tetapi juga berisi permohonan agar peserta ritual diberi keimanan yang kuat. Hal demikian, dapat menyebabkan seorang insan untuk selalu taat terhadap ajaran agamanya.

4. Nilai Intelektual dan Nilai Kecerdasan

Meskipun lahirnya ritual tolak bala pengobatan masyarakat Melayu Pantai Labu tidak lepas dari kepercayaan adanya mahluk gaib. Akan tetapi ritual ini juga menggiring pemilik tradisi untuk menggunakan akalnya dalam memahami posisi Tuhan dan mahluk gaib dalam kehidupan mereka. Mahluk gaib pada ritual ini hanya diposisikan sebagai zat pendukung bukan sebagai penentu tunggal terhadap permintaan yang diinginkan oleh manusia.

Maka, aspek-aspek yang terdapat dalam ritual tolak bala ini mencakup aspek religius, aspek sosial, dan aspek ekonomi.

4.3 Perubahan Fungsi dan Makna

Ritual Tolak Bala Pada Etnik

Melayu Pantai Labu

Berdasarkan teori komodifikasi, maka perubahan fungsi dan makna ritual tolak bala ini mengarah pada rangkaian tindakan, pembuatan atau pengolahan yang menghasilkan produk terkait dengan tuntutan yang

\begin{tabular}{|l|l|l|l|l|}
\hline No. & Item Perubahan & Dahulu & Sekarang & Aspek yang berubah \\
\hline 1 & Transformasi Nilai & Pantang larang & demokratis & Sikap terbuka \\
\hline
\end{tabular}

menyebabkan komodifikasi ritual tolak bala, fungsi produksinya, varian bentuk yang dihasilkan oleh pawang dan pemasaran produk hingga konsumen ritual tolak bala.

Sebagian masyarakat di Kecamatan Pantai Labu Kabupaten Deli Serdang masih mempercayai ritual tolak bala untuk pengobatan penyakit melalui pawang, sebagaimana tugas pengobatan sepenuhnya dari turun-temurun dipercayakan kepada pawang. Hal keadaan ini juga diperjelas dengan pernyataan Richard Winstead dalam bukunya "The Malay Magician: Being Shaman, Saiva and Sufi" sebagai berikut.

The Malays of the Peninsula often use different names for magicians in general (pawang) and those (bomor) who practise medicine only, and in Perak and Kelantan different names are given to the ordinary magician (pawang) and the shaman (belian). (Winstead R, 1951:11)

\subsection{Proses Pembuatan Ritual Tolak} Bala

Dalam hal ini peneliti mengungkapkan produksi ritual tolak bala dari segi produk ritual tolak bala berupa sesajian yang terdiri dari bambu kuning, kain putih, air putih, kelapa muda, belerang, limau purut, garam, kunyit, jerangau, ingu, jadam, merica, kemenyan, pisang, bermacam bunga dan beras putih.

4.5 Aspek-Aspek Penyebab Perubahan Fungsi dan Makna Ritual Tolak Bala

Ada beberapa aspek penyebab ritual tolak bala mengalami perubahan fungsi dan makna diantaranya berupa sikap terbuka, kreativitas masyarakat, media massa, dan ekonomi, sebagaimana dijelaskan dalam tabel berikut. 


\begin{tabular}{|l|l|l|l|l|}
\hline 2 & Penemuan & monoton & bervariasi & Kreativitas masyarakat \\
\hline 3 & Globalisasi & Tidak ada & berkembang & Media massa \\
\hline 4 & Mata pencaharian & $\begin{array}{l}\text {-berladang } \\
\text {-nelayan }\end{array}$ & bervariasi & Ekonomi \\
\hline
\end{tabular}

Tabel 1. Aspek-Aspek Perubahan Sosial Budaya

4.6 Faktor Perubahan Fungsi dan Makna Ritual Tolak Bala Untuk Pengobatan Penyakit mencakup:

\section{Faktor Eksternal}

Faktor Teknologi dan Media

Faktor Pendidikan

Faktor Ekonomi

2. Faktor Internal

Tidak adanya transmisi budaya dari generasi tua kepada generasi muda

Tidak adanya pengetahuan generasi muda tentang ritual tolak bala

Faktor Tradisi

4.7 Dampak dan makna perubahan ritual tolak bala pengobatan penyakit dalam masyarakat Melayu Pantai Labu mencakup:

1. Dampak:

Dampak Sosial

Dampak Ekonomi
Dampak Budaya

2. Makna:

Makna Religius

Makna Solidaritas

Makna Kedamaian

4.8 Dampak dan makna komodifikasi ritual tolak bala mencakup:

Komersialisasi ritual tolak bala

Kaburnya identitas budaya

Pelestarian Budaya

4.9 Strategi Pewarisan Dan Upaya Revitalisasi Ritual Tolak Bala

Sebagai langkah strategi pewarisan yang dilakukan oleh masyarakat Melayu Pantai Labu terhadap keberadaan ritual tolak bala yaitu dalam upaya (1) pemberdayaan, (2) pendokumentasian dan pengembangan.

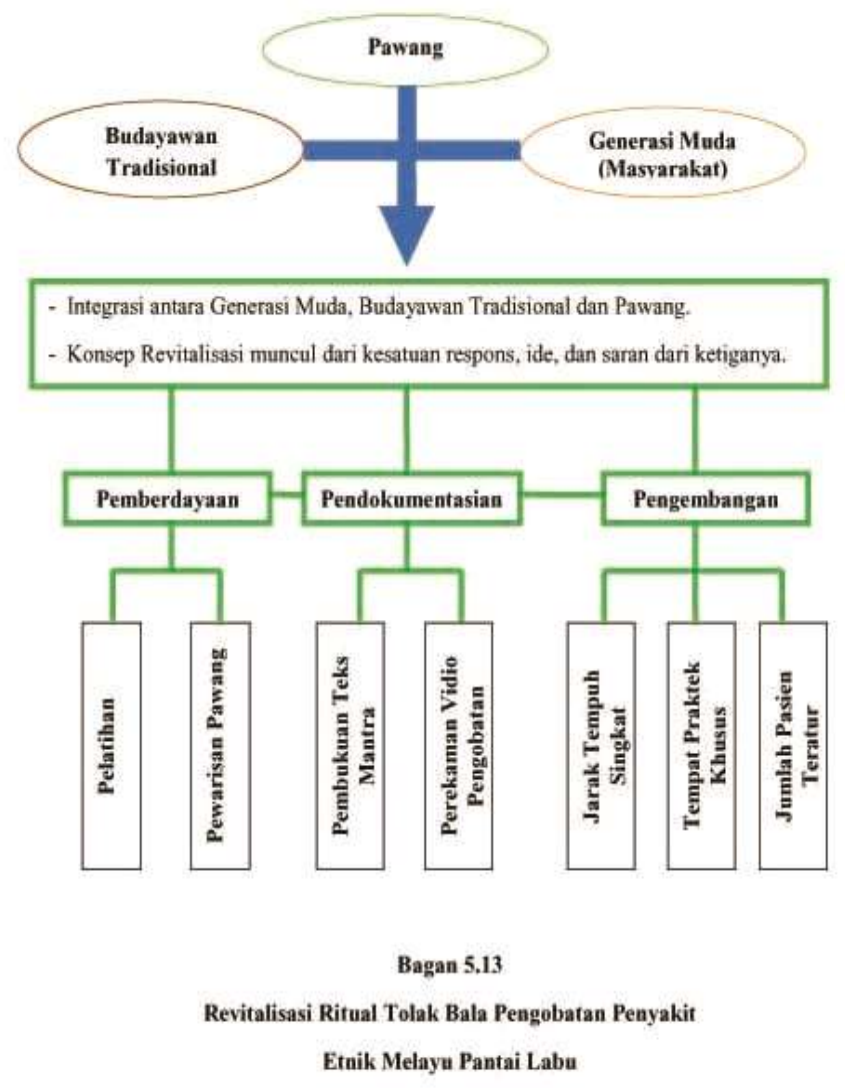




\section{KESIMPULAN}

Ritual tolak bala pada dasarnya dilaksanakan pada etnik Melayu Pantai Labu yang memiliki garis ketururunan yang sama (Melayu Pantai Labu). Ritual tolak bala memiliki tujuan untuk meminta kesembuhan atau kekuatan dalam pengobatan dari berbagai penyakit yang secara medis tidak bisa disembuhkan. Untuk memohon permintaan keselamatan, diwujudkan dalam bentuk upacara keagamaan/ritual. Ritual tolak bala memiliki banyak nilai dan makna yang berkaitan dengan kehidupan masyarakat laut yang pada proses pelaksanaannya memerlukan waktu yang relatif lama.

Seiring dengan kemajuan zaman, ritual tolak bala mengalami perubahan akibat persinggungan budaya lokal (Melayu Pantai Labu) dan budaya moderen (global) yang mengakibatkankan ritual tolak bala mengalami pergeseran dari sakralitas menuju profanisasi. Ideologi kapitalisme yang masuk ke ranah nilainilai tradisi masyarakat Melayu Pantai Labu ikut mempengaruhi ideologi masyarakat Melayu Pantai Labu akan sebuah nilai budaya yang dapat dijadikan sebuah komoditi yang pastinya bernilai jual sehingga ritual tolak bala mengalami pergeseran sehingga memunculkan praktik komodifikasi.

Adapun faktor yang meyebabkan komodifikasi ritual tolak bala pada etnik Melayu Pantai Labu yaitu sikap masyarakatnya yang terbuka dengan hal-hal baru melalui kontak budaya yang menimbulkan akulturasi sehingga mengakibatkan paradigma masyarakatnya berubah menyesuaikan dengan konteks masyarakat moderen yang memanfaatkan produk budaya (ritual tolak bala) untuk dijadikan barang/jasa yang bernilai jual.

\section{DAFTAR PUSTAKA}

Barker, Chirs. 2005. Cultural Studies, Teori dan Praktik (terjemahan). Yogyakarta: PT. Bentang Pustaka.

Daeng, Hans. 2000. Atropologi Budaya. Nusa Indah.

Danandjaja, James. 2002. Folklor Indonesia. Jakarta: PT. Temprint.

Endraswara, Suwardi. 2003. Metodologi Penelitian Kebudayaan. Yogyakarta: Gadjah Mada University Press.

Fairclough, Norman. 1995. Discourse and Social Change. Cambridge: Polity Press.

Giddens, A. 2003. Masyarakat Post Tradisional. Yogyakarta: IRCiSoD

Havilan, William A, 1993. Antropologi II, alih bahasa, R.G. Soekadijo, Jakarta : Erlangga.

Hoed, Benny H. 2004. Semiotik dan Dinamika Sosial Budaya. Jakarta: FIB-UI

Koentjaraningrat. 1987. Pengantar Ilmu Antropologi. Jakarta: Rineka Cipta.

Koentjaraningrat. 1993. Pengantar Ilmu Antropologi. Jakarta: Rineka Cipta.

Muhadjir, Noeng. 2000. Metodologi Penelitian Kualitatif Edisi IV. Yogyakarta: Rake Sarasin.

Turner, Bryan S. 1992. Max Weber: From History to Modernity. London: Routledge.

Winstedt, R. O. 1951. Malay Magician: Being Shaman, Saiva and Sufi, revised ed. London: Routledge \& Kegan Paul. 